\title{
Temperature dependence of the absolute rate constant for the reaction of ozone with dimethyl sulfide
}

\author{
WANG Hai-tao, ZHANG Yu-jie, MU Yu-jing* \\ Research Center for Eco-Environmental Sciences, Chinese Academy of Sciences, Beijing 100085, China. E-mail: yjmu@ rcees.ac.cn
}

Received 26 January 2007; revised 9 March 2007; accepted 28 March 2007

\begin{abstract}
Absolute rate constants for the reaction of ozone with dimethyl sulfide (DMS) were measured in a 200-L Teflon chamber over the temperature range of 283-353 K. Measurements were carried out using DMS in large excess over ozone of 10 to 1 or greater. Over the indicated temperature range, the data could be fit to the simple Arrhenius expression as $k_{\mathrm{DMS}}=(9.96 \pm 3.61) \times$ $10^{-11} \exp (-(7309.7 \pm 1098.2) / T) \mathrm{cm}^{3} /($ molecule $\cdot \mathrm{s})$. A compared investigation of the reaction between ozone and ethene had a $k_{\mathrm{C}_{2} \mathrm{H}_{4}}$ value of $(1.35 \pm 0.11) \times 10^{-18} \mathrm{~cm}^{3} /($ molecule $\cdot \mathrm{s})$ at room temperature.
\end{abstract}

Key words: rate constants; ozone; dimethyl sulfide (DMS); ethene

Dimethyl sulfide (DMS) is mainly produced by planktonic algae in sea water and a major source of cloudcondensation nuclei $(\mathrm{CCN})$ over the oceans (Charlson et al., 1987). The vast majority of DMS released into the atmosphere are removed by chemical reaction with OH (Cox and Sandalls, 1974; Kurylo, 1978; Niki et al., 1983); $\mathrm{Cl}$ (Stickel et al., 1986; Tyndall et al., 1986; Nielsen et al., 1990; Kinnison et al., 1996) and $\mathrm{NO}_{3}$ (Atkinson et al., 1984; Tyndall et al., 1986; Wallington et al., 1986) radicals. Ozone is also an important oxidant in the atmosphere and responsible for consuming varieties of gas species. Only upper limit value for the reaction between DMS and $\mathrm{O}_{3}$ at room temperature was reported in the literature (Martinez and Herron, 1978) and no temperature dependence of the rate constant of the reaction was available until now. On the basis of the only measurement for the reaction (Martinez, 1978), the NASA (National Aeronautices \& Space Administration) kinetic data evaluation panel suggested an upper limit of $<1.0$ $\times 10^{-18} \mathrm{~cm}^{3} /$ (molecule.s). Considering the background concentration of $\mathrm{O}_{3}(40 \mathrm{ppbv})$ is approximately $10^{6}$ times of the concentration of $\mathrm{OH}$ radicals, the reaction of $\mathrm{O}_{3}$ with DMS based on the upper limit could compete with the reaction of $\mathrm{OH}$ with DMS. Therefore, to better understand the contribution of $\mathrm{O}_{3}$ to the loss of DMS, the exact rate constant of the reaction is needed.

In this work, we investigated the rate constants for the reaction of ozone with DMS in the temperature range 283-353 K by using pseudo first order reaction method.

Foundation item: The National Natural Science Foundation of China (No 20677067, 20577064) and the National Basic Research Program (973) of China (2005CB422206) *Corresponding author.

E-mail: yjmu@rcees.ac.cn.
In addition, the rate constant of ethene with $\mathrm{O}_{3}$ at room temperature was also measured to examinate the reliability of our method. The atmospheric implication based on our experimental results was discussed.

The apparatus and experimental procedures have been described elsewhere (Wu et al., 2003) and will only be summarized here. Briefly, the experiments were carried out in an approximately 200-L heat-sealed Teflon bag, which was hung inside a chamber (ca. 3000 L). A pair of electric fans were positioned on the opposite inner walls of the chamber ensure that a uniform temperature can be maintained during reaction of the mixture. An electrothermal strip $(2.6 \mathrm{~cm}$ in width and $600 \mathrm{~cm}$ in length, 600 W, BQ 16B , Shanghai Qianwu Wiring Factory) surrounded the inner charmber for heating. In all cases, the temperature variation in the chamber was maintained to be within $\pm 1.5^{\circ} \mathrm{C}$.

The required amounts of DMS and ethene were intruduced into the Teflon bag by sweeping a calibrated volume contained the reactants with a stream of air. Ozone was introduced into the bag using an ozone generator (AO12, Aijia Machine Factory, Shanghai, China). After mixing of the reactants in the bag, the ozone concentrations were monitored as a function of time by an ozone analyzer (model 8810, Monitor Labs Inc.). A gas chromatograph (GC-6AM, Shimadzu, Japan) equipped with a flame photometer detector (FPD) was used for DMS quantitative analysis. DMS in the reaction mixtures were separated on a $3 \mathrm{~m} \times 4 \mathrm{~mm}$ glass column packed with $20 \%$ SE 30 on Chromosorb P (60-80 mesh). The column temperature was held at $50^{\circ} \mathrm{C}$. The injection port temperature and the detector temperature were $180^{\circ} \mathrm{C}$ and $240^{\circ} \mathrm{C}$, respec- 
tively. Typical gas flow rates were: nitrogen (carrier gas, $99.999 \%$ ), $40 \mathrm{~cm}^{3} / \mathrm{min}$; hydrogen, $45 \mathrm{~cm}^{3} / \mathrm{min}$; air, 45 $\mathrm{cm}^{3} / \mathrm{min}$. A gas chromatograph (GC4410, East \& West Analytical Instrument Inc., Beijing, China ) equipped with a photoionization detector (PID) was used for ethene quantitative analysis. Ethene in the reaction mixtures were separated on a $2 \mathrm{~m} \times 3 \mathrm{~mm}$ Teflon column packed with GDX 203 (60-80 mesh ) at a column temperature of $40^{\circ} \mathrm{C}$.

Ozone reaction rate constants were determined by monitoring $\mathrm{O}_{3}$ decay in the presence of known concentrations of the reactants. $\mathrm{O}_{3}$ loss paths in the chamber can be considered as follows:

$\begin{array}{ll}\mathrm{O}_{3}+\text { wall } \longrightarrow \text { loss of } \mathrm{O}_{3} & k_{0} \\ \mathrm{O}_{3}+\text { reactant } \longrightarrow \text { loss of } \mathrm{O}_{3} & k_{1}\end{array}$

Under the experimental conditions, $\mathrm{O}_{3}$ concentrations of $(0.25-1.97) \times 10^{13}$ molecule $/ \mathrm{cm}^{3}$ were mixed with $(2.5-$ $49.8) \times 10^{14}$ molecule $/ \mathrm{cm}^{3}$ of reactants (DMS or ethene) in air. The concentrations of reactants were in all case 10 1000 times greater than that of $\mathrm{O}_{3}$; hence, the observed kinetics were pseudo-first order throughout the reaction:

$-\mathrm{d} \ln C_{\mathrm{O}_{3}}=k^{\prime} \mathrm{d} t$, where $k^{\prime}=k_{0}+k_{1} C_{\text {reactant }}$

Thus, $-\frac{\mathrm{d} \ln C_{\mathrm{O}_{3}}}{\mathrm{~d} t}$ were determined at various reactant concentrations.

The used chemicals were ethene $(\geqslant 95 \%$, Beijing Analytical Instrument Factory, China), dimethyl sulfide ( $\geqslant 99.0 \%$, Fluka). Dimethyl sulfide was further purified by repeat freeze, pump, and thaw cycles and fractional distillation before use.

The reaction between DMS and $\mathrm{O}_{3}$ were carried out in a $200-\mathrm{L}$ Teflon reaction chamber under different temperature. In all cases, exponential decays of ozone concentrations were observed. Fig. 1 shows the typical plots of $\ln C_{\mathrm{O}_{3}}$ versus time under different DMS concentrations. The corresponding plots of Equation (3) are shown in Fig.2. Good straight line plots were obtained, and the pseudo-first reaction rate constants could be derived from the slopes. The error bars express in Fig. 2 are two standard deviations taken from the linear least square fit of the

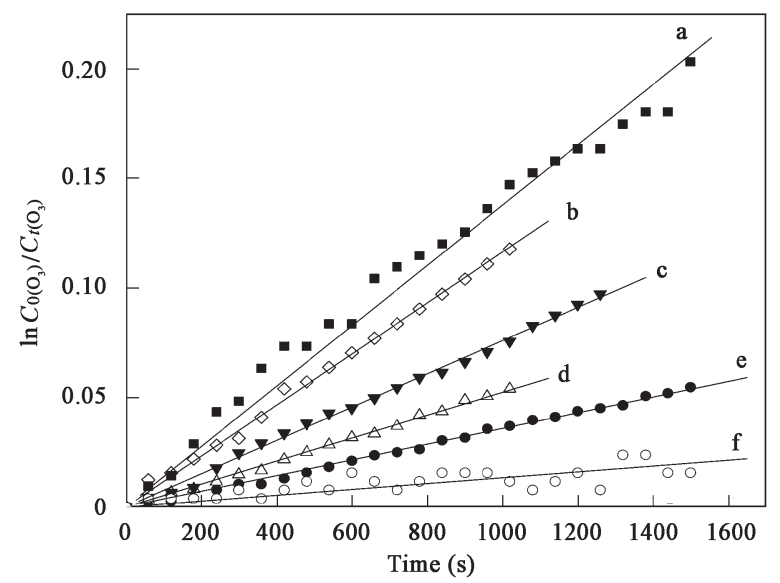

Fig. 1 Plot of $\ln C_{0\left(\mathrm{O}_{3}\right)} / C_{t\left(\mathrm{O}_{3}\right)}$ vs. reaction time under different concentrations of DMS at $298 \mathrm{~K}$. DMS concentrations $\left(\times 10^{15}\right.$ molecules $\left./ \mathrm{cm}^{3}\right)$ : (a) 9.15 ; (b) 7.79 ; (c) 5.25 ; (d) 3.48 ; (e) 1.30 and (f) 0 .

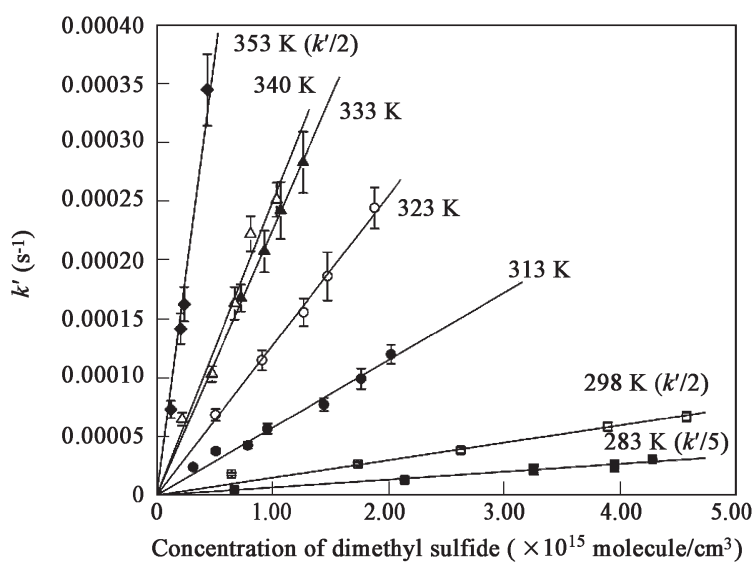

Fig. 2 Plot of the pseudo-first-order rate constant vs. concentration of DMS.

$\mathrm{O}_{3}$ decay rate versus $\mathrm{C}_{\text {DMs }}$ plus an additional estimates uncertainty $(5 \%)$ which was account for experimental variabillity due to mixture composition. These expanded error limits should, in the absence of any systematic errors, be a realistic appraisal of the $95 \%$ confidence limits.

The bimolecular rate constant of DMS at $298 \mathrm{~K}$ was derived as $(1.48 \pm 0.13) \times 10^{-20} \mathrm{~cm}^{3} /($ molecule.s $)$, which is approximately 2 orders magnitude lower than the upper limit of $1.0 \times 10^{-18} \mathrm{~cm}^{3} /$ (molecule $\left.\cdot \mathrm{s}\right)$ recommended by NASA. For DMS reactions, the aerosol formation may bring secondary reactions. Simple straight line pseudo-first order rate plots can not overrule the secondary reactions. But the rate constant value of DMS at $298 \mathrm{~K}$ we obtained is so small that the aerosol formation can be skipped.

The Arrhenius plot is shown in Fig.3 and the Arrhenius expression in $\mathrm{cm}^{3} /$ (molecule.s) over the temperature range of $283-353 \mathrm{~K}$ derived from the plot is: $k_{\mathrm{DMS}}=$ $(9.96 \pm 3.61) \times 10^{-11} \exp (-(7309.7 \pm 1098.2) / T)$.

Where, the error limits quoted above are one standard deviation of the fit of the points $k \pm(2 \sigma+0.05 k)$ at each temperature as shown in Fig.3. It is evident that the reaction of DMS with ozone is positively dependent on temperature.

On the basis of our experimental results, the atmospheric lifetime of DMS due to $\mathrm{O}_{3}$ attack will be about more than 2 years assuming an average $\mathrm{O}_{3}$ concentration of $1.0 \times 10^{12}$ molecules $/ \mathrm{cm}^{3}$ in the background area. Thus, the

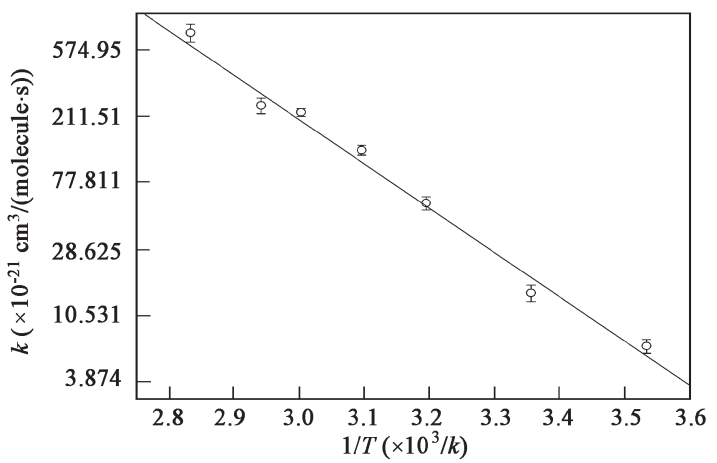

Fig. 3 Arrhenius plot for the reaction of $\mathrm{O}_{3}$ with DMS. Each data point is based on 4-7 experiments at each temperature. 


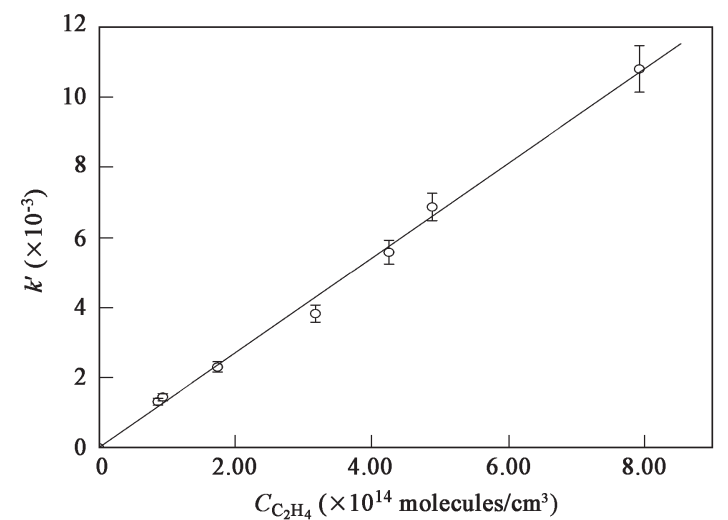

Fig. 4 Plot of the pseudo-first-order rate constant vs. the concentration of $\mathrm{C}_{2} \mathrm{H}_{4}$.

contribution of $\mathrm{O}_{3}$ to DMS loss in the atmosphere is only accounted for $0.2 \%$ compared with the reaction of $\mathrm{OH}$ $\left(C_{\mathrm{OH}}: 1.0 \times 10^{6}\right.$ molecules $\left./ \mathrm{cm}^{3}\right)$ with $\mathrm{DMS}$, and could be negligible.

To examinate the reliability of this method, the rate constant of the reaction of ethene with $\mathrm{O}_{3}$ at room temperature $(298 \mathrm{~K})$ was also measured as $(1.35 \pm 0.11) \times 10^{-18}$ $\mathrm{cm}^{3} /$ (molecule.s) (Fig.4) which is in good agreement with the values reported in literature (Atkinson et al., 1997), providing the circumstance that the method used by this study is reliable. The calculated tropospheric lifetime of ethene with respect to $\mathrm{O}_{3}$ is approximately $9 \mathrm{~d}$ at $298 \mathrm{~K}$ for $\mathrm{O}_{3}$ concentrations of $1.0 \times 10^{12}$ molecules $/ \mathrm{cm}^{3}$.

As a conclusion, the reaction rate constants of the reaction between DMS and $\mathrm{O}_{3}$ over the temperature range of $283-353 \mathrm{~K}$ were measured by using smog chamber technique in this study. The exact rate constants and temperature dependence for the reaction were first reported. Our results indicated that the influence of $\mathrm{O}_{3}$ on DMS loss in the troposphere was negligible.

\section{References}

Atkinson R, Jr Pitts J N, Aschmann S M, 1984. Tropospheric reactions of dimethyl sulfide with $\mathrm{NO}_{3}$ and $\mathrm{OH}$ radicals [J]. J Phys Chem, 88: 1584-1587.

Charlson R J, Lovelock J E, Andreae M O et al., 1987. Oceanic phytoplankton, atmospheric sulphur, cloud albedo and climate[J]. Nature, 326: 655-661.

Cox R A, Sandalls F J, 1974. The photo-oxidation of hydrogen sulphide and dimethyl sulphide in air[J]. Atmos Environ, 8: 1269-1281.

Kinnison D J, Mengm W, Kerr J A et al., 1996. Rate coefficients for the room temperature reaction of $\mathrm{Cl}$ atoms with dimethyl sulfide and related alkyl sulfides[J]. J Chem Soc Faraday Trans, 92: 369-372.

Kurylo M J, 1978. Flash photolysis resonance fluorescence investigation of the reaction of $\mathrm{OH}$ radicals with dimethyl sulfide[J]. Chem Phys Letters, 58: 233-237.

Martinez R I , Herron J T, 1978. Stopped-flow study of the gasPhase reaction of ozone with organic sulfides: Dimethyl sulfide[J]. Int J Chem Kinet, 10: 433-452.

Nielsen O J, Sidebottom H W, Nelson L et al., 1990. Rate constants for the reactions of $\mathrm{OH}$ radicals and $\mathrm{Cl}$ atoms with dimethyl sulfide, di- $n$-propyl sulfide, and di- $n$-butyl sulfide [J]. Int J Chem Kinet, 22: 603-612.

Niki H, Maker P D, Savage C M et al., 1983. An FTR study of the mechanism for the reaction $\mathrm{HO}+\mathrm{CH}_{3} \mathrm{SCH}_{3}[\mathrm{~J}]$. Int $\mathrm{J}$ Chem Kinet, 15: 647-654.

Stickel R E, Nicovich J M, Wang S et al., 1986. Kinetic and mechanistic study of the reaction of atomic chlorine with dimethyl sulfide[J]. J Phys Chem, 86: 9875-9883.

Tyndall G S, Burrows J P, Schneider W et al., 1986. Rate coefficient for the reaction between $\mathrm{NO}_{3}$ radicals and dimethyl sulphide[J]. Chem Phys Lett, 130: 463-466.

Wallington T J, Atkinson R, Winer A M et al., 1986. Absolute rate constants for the gas-phase reactions of the $\mathrm{NO}_{3}$ radical with $\mathrm{CH}_{3} \mathrm{SH}, \mathrm{CH}_{3} \mathrm{SCH}_{3}, \mathrm{CH}_{3} \mathrm{SSCH}_{3}, \mathrm{H}_{2} \mathrm{~S}, \mathrm{SO}_{2}$, and $\mathrm{CH}_{3} \mathrm{OCH}_{3}$ over the temperature range $280-350 \mathrm{~K}[\mathrm{~J}]$. J Phys Chem, 90: 5393-5396.

Wu H, Mu Y, Zhang X et al., 2003. Relative rate constants for the reactions of hydroxyl radicals and chlorine atoms with a series of aliphatic alcohols[J]. Int J Chem Kinet, 35: 81-87.

Atkinson R, Baulch D L, Cox R A et al., 1997. Evaluated kinetic, photochemical and heterogeneous data for atmospheric chemistry: supplement V, IUPAC subcommittee on gas kinetic data evaluation for atmospheric chemistry[J]. J Phys Chem Ref Data, 26: 521-1011. 